\title{
AGRUPACIONES ALTERNATIVAS DE TRANSPORTES EN COSTA RICA
}

\section{ALTERNATIVE TRANSPORTATION ORGANIZATIONS IN COSTA RICA}

\author{
Adriana Sánchez Lovell*
}

\author{
RESUMEN
}

El presente artículo ${ }^{1}$ reúne una discusión respecto a la conformación, objetivos, campo de acción y relevancia de las organizaciones alternativas de transporte en Costa Rica. Su existencia se considera vital para la defensa en materia de derechos de acceso al transporte $y$ para colaborar y presionar por que se implementen medidas preventivas de seguridad vial, a niveles político, legal, social e infraestructural. Se considera importante que la academia incorpore en la discusión y en las actividades que promueve a organizaciones como estas, en tanto vehiculizan la participación social y el mejoramiento en las condiciones de traslado de la población general.

PALABRAS CLAVE: COSTA RICA * ORGANIZACIONES VOLUNTARIAS * TRANSPORTE * SEGURIDAD EN LAS CARRETERAS * EQUIDAD

\section{ABSTRACT}

This paper summarizes a discussion about the configuration, action, and actual relevance of alternative transportation organizations in Costa Rica. These organizations claim to fight for an improvement in the exercise of mobility rights for everyone. At the same time, they put pressure for the implementation of safety measures in the political, legal, social, and infrastructural spheres that comprise sustainable transportation.

\section{KEYWORDS: COSTA RICA $*$ VOLUNTARY ORGANIZATIONS $*$ TRANSPORT $*$ ROAD SAFETY} * EQUALITY

* Instituto de Investigaciones Sociales de la Universidad de Costa Rica adrilovell@gmail.com

1 El artículo se inspira en una mesa de discusión realizada el 4 de junio de 2010 con motivo de las celebraciones del Día Sin Humo, que nació como el Día del Transporte Sostenible hace cuatro años y se propone socializar y ampliar algunas discusiones que allí se dieron. Asimismo, se ha nutrido de las observaciones de José Luis Rodríguez Fournier, asistente de la investigación titulada "Dimensiones socioculturales del malestar vial en Costa Rica"; Mauricio Leandro, miembro fundador de Acaminar y Ramón Pendones de Pedro, fundador de Aconvivir. 


\section{INTRODUCCIÓN}

El presente artículo discute la conformación histórica de organizaciones alternativas del transporte en Costa Rica. Además, se indica cuáles son los objetivos y las acciones que han emprendido estas organizaciones, en materia de acceso a transportes para todo tipo de usuario, defensa de los derechos de las mayorías $y$ las iniciativas que se han implementado en cada una de ellas para ejercer presión o posibilitar la introducción, mejoramiento y mantenimiento de medidas de seguridad para la movilización humana en Costa Rica.

Las organizaciones a las cuales se hará referencia, son el Automóvil Club de Costa Rica (ACCR), la Asociación de deportistas contra la VIolencia Vial y el IRrespeto (Aconvivir) y la de más reciente constitución, Asociación Caminar (Acaminar). Para cada una varía el contexto de su constitución, por lo que el propósito de este artículo es dar a conocer las condiciones de su surgimiento, cuya comprensión se considera vital para comprender mejor sus metas, alcances y logros.

En primera instancia, se considera fundamental establecer una breve contextualización respecto a la situación actual de las manifestaciones de la violencia en el tránsito, que encuentra en los siniestros una de sus más graves consecuencias. Se subraya en la importancia de tomar medidas preventivas a nivel social e infraestructural; generar conciencia sobre la manera en que nos comportamos sobre las vías públicas y la necesidad de introducir mejoras infraestructurales en estas últimas. La educación y la prevención así como, carreteras aliadas de la vida humana son tres pilares de la salud pública y mental.

\section{CONTEXTO NACIONAL}

Mundialmente, el tránsito es considerado por la Organización Mundial de la Salud (OMS) como el sistema más peligroso al cual deben enfrentarse los individuos. En esto, Costa Rica no es la excepción, y las heridas ocasionadas por sucesos del tránsito conforman la principal causa de muerte violenta en el país así como, es uno de los principales generadores de discapacidad física a nivel nacional.

Haciendo énfasis en el tema de la prevención, es posible decir que el principal factor que contribuye a producir y reproducir violencia en el sistema de transportes costarricense, es la falta de planificación. Para hacerle frente, se requiere de políticas sistemáticas en seguridad vial basadas en información recopilada de manera rigurosa e investigaciones, la introducción de medidas y dispositivos de seguridad en la infraestructura vial, el impulso a la profesionalización en seguridad vial para todas las ramas del oficio, el planteamiento y la ejecución de programas intensivos de educación vial, seccionados por grupos específicos; así como, mejorar la rigurosidad de los exámenes con que se obtiene la licencia de conducir en el país. Sin embargo, la prevención es la principal herramienta con que cuenta la sociedad para hacerle frente al problema de las violencias en las carreteras.

Para introducir un marco que permita la interpretación de esto, cabe decir sin embargo, que en la producción de un siniestro del tránsito intervienen cuatro aspectos: el factor humano, el vehículo, la carretera y el ambiente ${ }^{2}$. Por lo tanto, para atender a los factores etiológicos de los sucesos del tránsito, es fundamental atender simultáneamente a la interacción entre estos cuatro factores así como, estudiar a fondo cada caso en específico.

Según Vargas y Solano (2008) del Departamento de Medicina Legal del Poder Judicial, han sido recientemente subestimadas las estadísticas de muerte a raíz de siniestros, $y$ plantean que al menos en el año 2007, estos ostentan un $25 \%$ de participación en la clasificación de causas externas de muerte, con una tasa de 16,58 defunciones por 100000 habitantes. Las caracterizaciones de las víctimas fueron consistentes con otros reportes del INS (2007) y cosevi (2008):

$2 \quad$ La matriz de Haddon fue propuesta por William Haddon Jr. (1999) quien sostuvo la necesidad de pasar de valorar el problema del trauma desde lo descriptivo a buscar explicaciones etiológicas desde una perspectiva científica. 
El perfil predominante de las víctimas fue: ser de género masculino, en edad económicamente productiva, con accidentes fatales de predominio en la noche, los fines de semana, en las provincias costeras, con fallecimiento en el sitio del hecho por trauma cráneo cervical en ocupantes de automotores o peatones, de los cuales un porcentaje significativo estaba bajo los efectos del alcohol y muy pocos bajo los efectos de otras drogas de abuso. Se insiste en la prevención como la herramienta fundamental para evitarlos (Vargas y Solano, 2008).

En tercer lugar, aunado a la concepción del tránsito como un sistema y la prevención como la principal herramienta que tenemos para evitar muertes y lesiones; las desigualdades sociales y económicas, son uno de los principales elementos que explican la vulnerabilidad y la exposición al riesgo. Históricamente en Costa Rica, cuando se promueve la construcción de carreteras, priman las nociones de "progreso" y traslado de mercancías sobre las necesidades de acceso y bienestar humano.

En este tópico, se hace evidente el nivel desigual de acceso a información e infraestructura de transporte en Costa Rica, para usuarios peatonales $y$ ciclistas frente a usuarios de automotores. Si a esto le sumamos, la falta de dispositivos de seguridad en ambos tipos de vía, se hace patente la urgencia de intervenir sobre estos aspectos. Dado el rezago que han tenido las instituciones estatales para resolver estos problemas, surgen las organizaciones alternativas de transportes en Costa Rica, las cuales velan por que haya más infraestructura para peatones y ciclistas; más semáforos peatonales, mayor inversión para ciclovías, aceras y educación vial para lo que incluso, una de ellas ha diseñado un manual de educación vial para ciclistas.

Tras este preámbulo, se procede a presentar $y$ discutir el papel de las agrupaciones alternativas de transportes en Costa Rica, las cuáles se reunieron el pasado 4 de junio, en el marco del conversatorio realizado por el Instituto de Investigaciones Sociales, con motivo de las celebraciones del Día sin Humo.

\section{LAS ORGANIZACIONES ALTERNATIVAS DE TRANSPORTE}

Las organizaciones alternativas de transporte en Costa Rica, son al menos tres agrupaciones que se ocupan de velar por los intereses de motoristas, peatones y ciclistas en el país. La primera en surgir fue el Automóvil Club de Costa Rica, en la década de los sesentas. Posteriormente, se fundan Aconvivir y Acaminar, en el siglo presente.

\section{A) EL AUTOMÓVIL CLUB DE COSTA RICA}

El Automóvil Club de Costa Rica ${ }^{3}$ (ACCR) surge a mediados de la década de los sesentas y a su vez, pertenece a una organización internacional, la Federación Internacional de Automovilistas (FIA), asociación sin fines de lucro en la que participan motoristas de 226 países de los cinco continentes. Su principal objetivo radica en la defensa de los automovilistas y de usuarios de automóviles en todo el mundo:

La FIA ha estado dedicada a representar los derechos de los automovilistas $y$ usuarios de automóviles en todo el mundo a través de campañas y actividades de defensa de sus intereses. En temas como seguridad, movilidad, medio ambiente $y$ el derecho de los consumidores de la FIA promueve activamente los intereses de los automovilistas en las Naciones Unidas, dentro de la Unión Europea $y$ de otros organismos internacionales (Federación Internacional del Automóvil, 2008).

Dicha agrupación promueve campañas por una conducción más ecológica, por carreteras seguras, por amor, por el uso de los cinturones de seguridad y las sillas especiales para niños y niñas así como, para promover consciencia y para que se tomen medidas de seguridad antes de conducir. Por ejemplo, la Campaña

3 La página oficial de Automóvil Club de Costa Rica es: <http://www.automovilclubcr.com/vial.html> 
de Carreteras Seguras ${ }^{4}$ (Make Roads Safe) promueve que "los traumatismos causados por el tránsito se incorporen a las agendas para el desarrollo sostenible de la G8 y las Naciones Unidas" y se presentó hace algunos años ante la Organización de Naciones Unidas (ONU). Dicha campaña, está a cargo de una coalición de organizaciones relacionadas con la seguridad vial y la salud pública. El fin de la misma, consiste en concientizar a la gente y a los representantes políticos, respecto a la letalidad asociada con los siniestros del tránsito, los cuales cobran al menos la vida de 3000 personas y 500 niños diariamente en el mundo. El 80\% de las defunciones ocurren en países de ingresos medios $y$ bajos como Costa Rica, lo que refleja como las desigualdades que se mencionaron anteriormente, potencian la vulnerabilidad y el riesgo en las vías públicas ${ }^{5}$.

\section{B) ACONVIVIR}

Aconvivir ${ }^{6}$ es una asociación sin fines de lucro fundada por ciclistas víctimas de atropellos causados por conductores en estado de ebriedad. A través de los años de existencia de la organización, se les han sumado otros miembros que incluyen políticos y deportistas de competición. Los orígenes de Aconvivir datan del año 2007.

Aconvivir surge en resguardo de los profesionales en ciclismo, ante la realidad nacional en carreteras que no deja de cobrar víctimas de todo tipo $y$ de todas las clases sociales $y$ actualmente,

$4 \quad$ La página oficial de la campaña es: <http://www. makeroadssafe.org/Pages/home.aspx >

5 También la campaña persigue el objetivo de que la G8 y las Naciones Unidas se comprometan en la ejecución de un plan de acción de alto nivel, de un costo de 300 millones de dólares para ejecutar en un periodo de 10 años, con el fin de mejorar la seguridad vial en los países en vías de desarrollo. Se busca que el 10\% del presupuesto de préstamos $y$ donaciones para el desarrollo destinado a la construcción y mejoramiento de carreteras, sea destinado a la seguridad vial (Automóvil Club de Costa Rica).

Para más información sobre Aconvivir puede consultar en la dirección: <http://www.aconvivir.org/> se atribuyen la defensa de los derechos de toda la población, en espacios públicos, carretera $y$ aceras. La organización ha venido creciendo, ahora cuenta con 600 miembros y siguen sumándosele otros (Aconvivir.org).

La misión de la organización es promover la convivencia pacífica, así como, la tolerancia entre los diferentes usuarios de nuestras carreteras, aceras y espacios públicos en general. La visión que construyen es la de una sociedad respetuosa, tolerante y no violenta en las carreteras y espacios públicos. De manera que los valores que la caracterizan son los del respeto, la tolerancia y la sana convivencia entre los usuarios del espacio público, la responsabilidad vial y social y el de mejorar la calidad de vida del costarricense.

El objetivo de la organización es:

Prevenir accidentes viales que involucran vehículos no motorizados y peatones para alcanzar una sociedad respetuosa, tolerante $y$ sin violencia en las carreteras y espacios públicos por medio de la educación vial y la adecuación de las leyes a la realidad nacional (Aconvivir, 2008: 6).

Los objetivos específicos son, parafraseando, el fomento de espacios seguros para la movilización y el esparcimiento; promover reformas a la Ley de Tránsito para promover la reducción de sucesos violentos, así como, para incidir en la cultura, mediante medidas encaminadas a luchar contra la agresión, el irrespeto, la negligencia y la imprudencia; hacer una campaña en los medios para concientizar acerca del problema de la violencia en las carreteras, crear programas de educación y responsabilidad social para todos los usuarios de las vías públicas terrestres y finalmente, promover el uso de transportes no motorizados, por el bien de la ecología y la salud humana (Aconvivir.org).

En la práctica, Aconvivir es una agrupación que ha liderado actividades como el patrocinio de atletas con habilidades especiales, adquiridas a causas de lesiones del tránsito; campañas para el aprendizaje de medidas de seguridad para ciclistas, campañas de repartición de implementos de seguridad para ciclistas 
en escuelas y empresas, así como, fomentan la construcción de ciclovías mediante el diseño y la propuesta de la implementación de las mismas ante las entidades políticas concernientes (Aconvivir.org).

Pasando a especificar algunos de estos aportes, en el tema de la promoción de Reformas a la Ley de Tránsito, Aconvivir ha promovido que las ciclovías se conceptualicen como componentes fundamentales de seguridad vial en los proyectos de infraestructura vial, que se instale rotulación preventiva de "ciclistas en la vía" en zonas de tránsito común por parte de este tipo de usuarios y que se limite la velocidad máxima a $40 \mathrm{KPH}$ en zonas de afluencia de ciclistas. También acaban de presentar recientemente (2010) una propuesta técnica de Reforma a la Ley de Tránsito en coordinación con la Defensoría de los Habitantes, el Instituto sobre Alcoholismo y Farmacodependencia (IAFA), el Colegio Federado de Ingenieros y de Arquitectos (CFIA) y el Colegio de Farmacéuticos (Aconvivir.org).

En términos de la promoción de la educación vial y el respeto, ostenta la publicación de un manual para ciclistas (el Manual del buen ciclista $)^{7}$, y campañas nacionales como ¡Las calles son de todos, comparta la vía! ${ }^{8}$, así como, ¡Yo salvé un ciclista: un casco para el prójimo! ${ }^{9}$ (Aconvivir.org).

$7 \quad$ El Manual se puede descargar de forma gratuita en: <http://aconvivir.org/documentos/manual_ buen $\% 20$ ciclista.pdf $>$

Para acceder a la campaña en su versión escrita puede visitar el link: <http://aconvivir.org/ documentos/las_calles_son_de_todos_comparta_la_via.pdf $>$. El componente audiovisual se puede acceder en: <http://www.youtube.com/ watch? $v=g J T 4 \mathrm{dA} 2 \mathrm{WLX} 4>$.

9 Para obtener información adicional se puede visitar la página oficial de la agrupación o accesando el
Algo muy importante de recalcar es el Programa Nacional ¡Completemos las calles! ${ }^{10}$, actualmente en periodo de ejecución del plan piloto, en las comunidades de Santa Marta de Montes de Oca y Granadilla de Curridabat, que busca incrementar las condiciones de seguridad para todo tipo de usuario. Como parte de esta campaña, Aconvivir ha coordinado con el MOPT la colocación de señales que indiquen la presencia de ciclistas en la vía y de límites de velocidad máxima de $40 \mathrm{KPH}$, en la zona del "plano" de Cartago. No menos importante es el diseño de una ciclovía (ver Figura 1), que abarcaría desde la Universidad de Costa Rica en San Pedro, hasta La Sabana (Aconvivir.org).

Aconvivir ha lanzado recientemente el Manual del buen ciclista, liderado por el lema: "si no sos parte de la solución, sos parte del problema”. El manual se compone de imágenes e indicaciones tanto respecto a los dispositivos de seguridad que deben tener las bicicletas para ser un medio de transporte seguro como lineamientos acerca de la manera adecuada de transitar en este medio por la vía pública. Este contiene indicaciones para situaciones específicas a las que puede enfrentarse un ciclista, consejos acerca de las vías más seguras para transitar, advertencias para el uso de semáforos y el cruce de vías así como, consejos que pueden seguir los ciclistas para evitar ciertas formas de colisión comunes para este tipo de usuarios, tales como el choque contra las puertas de automotores (Aconvivir, 2008).

link < http://aconvivir.org/documentos/yo_salve_ un_ciclista.pdf > content\&task=view\&id $=28 \&$ Itemid $=1>$ 
FIGURA 1

DISEÑO DE CICLOVÍA, SAN PEDRO-LA SABANA ${ }^{11}$
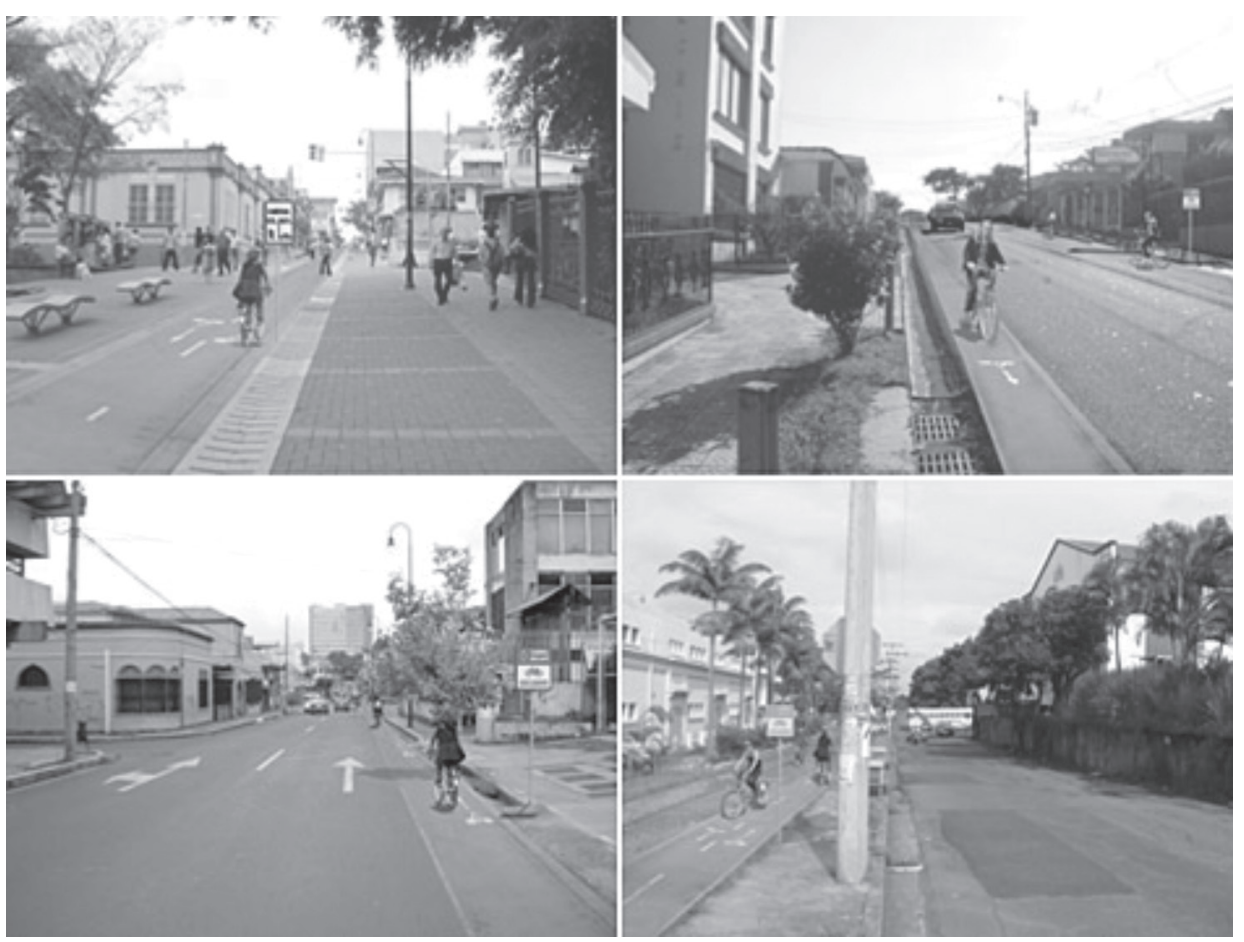

11

Tomado de: <www.Aconvivir.org/>

\section{C) ASOCIACIÓN CAMINAR}

Acaminar ${ }^{12}$ es una asociación de personas que se desplazan a pie como principal medio de transporte. Con sede en Costa Rica, ACAMINAR forma parte de la Federación Mundial de Personas a Pie (International Federation of Pedestrians), cuyo motivo de ser radica en "promover y defender el derecho del peatón y la peatona a pleno acceso y la movilidad".

Surgió a partir de la iniciativa de un grupo de pedestres comprometidos con la causa de quienes transitan a pie, por lo general en condiciones de desigualdad en Costa Rica y el mundo. De acuerdo con la exposición de Mauricio Leandro, miembro fundador, las personas que se desplazan a pie son una mayoría

12. Para establecer contacto con Acaminar se puede dirigir a la dirección movisos@gmail.com o visitar la página Acaminar: <http://www.acaminar.org/> en este país, pero atraviesan la contradicción de que por lo general, éstos y éstas no cuentan con todos los dispositivos necesarios para su movilización saludable, pronta y equitativa. Dispositivos básicos como aceras, puentes peatonales, semáforos, vías libres de obstáculos y conductores respetuosos de la vida humana, es parte de lo que esta asociación reclama.

Acaminar es una asociación que apenas se encuentra en su etapa de formación, por lo que más que plantear sus logros vamos a profundizar en algunos de sus retos. Los fines para los cuales fue creada ACAMINAR son: incrementar la movilidad integral, diseñar $y$ procurar espacios y lugares para las personas que caminan, lograr una adecuada integración de las redes peatonales, promover el planeamiento espacial y usos del suelo en apoyo a la movilización a pie, reducir el peligro de atropellos, contribuir a mejorar la sensación de seguridad personal de quienes se 
desplazan a pie, aumentar el apoyo de las instituciones hacia la peatonización y procurar una cultura del caminar en todo el territorio nacional.

La Asociación Caminar reclama el derecho a que el espacio público se distribuya equitativamente. Si se toma en cuenta que no más del $25 \%$ de los habitantes acapara más del 70\% del espacio dedicado a la movilidad pues posee algún medio de transporte privado, es claro que hay una situación de injusticia ambiental sostenida. Para los fundadores de la Asociación Caminar, el tema de las personas a pie por lo general es invisible en las discusiones relativas al desarrollo de infraestructura y servicios destinados a mejorar la movilidad. Esto se relaciona directamente con una visión política basada en el uso no equitativo del espacio público y por tanto una violación continua del artículo 50 de la Constitución Política ya que en el mismo se asegura que el Estado procurará "el más adecuado reparto de la riqueza”. Para la Asociación Caminar, el espacio público es una de las mayores riquezas que comparten los habitantes de la República, sobre todo quienes viven en los centros urbanos. El mismo artículo 50 de la Constitución garantiza que "toda persona tiene derecho a un ambiente sano y ecológicamente equilibrado". Por ello, está legitimada para denunciar los actos que infrinjan ese derecho y para reclamar la reparación del daño causado (Reforma Constitucional 7412 de 3 de junio de 1994).

Para trasladar la exposición de las dimensiones que toma el problema de la falta de infraestructura para peatones y peatonas, cabe examinar tres casos específicos de la vía pública, $y$ mencionar las dinámicas que se generan en la Ruta 2 (sector San Pedro).

Efectivamente, en sitios como la fuente de la Hispanidad, se genera una serie de dinámicas que dan cuenta de la falta de planificación en infraestructura para peatones. Primero, muchas personas cruzan principalmente en dirección Este-Oeste y Norte-Sur por ambas direcciones, tomando como punto de referencia el Mall San Pedro. En el segundo caso, esto es muy peligroso pues la autopista contiene cinco carriles $y$ a esto se suma un muro que divide las vías contrarias, duplicando el riesgo cuando la gente se ve obligada a atravesarlo. La misma situación se presenta en los costados Noreste, Oeste y Sureste de la Hispanidad, que constituyen junto con el costado Noroeste, los principalmente sectores por los cuales los peatones suelen cruzar. En las tres primeras vías mencionadas el Estado incurre en negligencia, pues dichos puntos están desprovistos de infraestructura peatonal. Solo en la vía Norte-Sur se puede señalar que existe un alto nivel de imprudencia por parte de los peatones, puesto que hay un paso peatonal a menos de 200 metros para atravesar la calle principal que se dirige al centro de San José, ya sea en el sentido Norte-Sur o Sur- Norte. Sin embargo, habría que analizar que tan óptima es su ubicación (véase la Figura 2). 
FIGURA 2

FALTA DE PLANIFICACIÓN INFRAESTRUCTURAL PARA PEATONES Y PEATONAS, HISPANIDAD

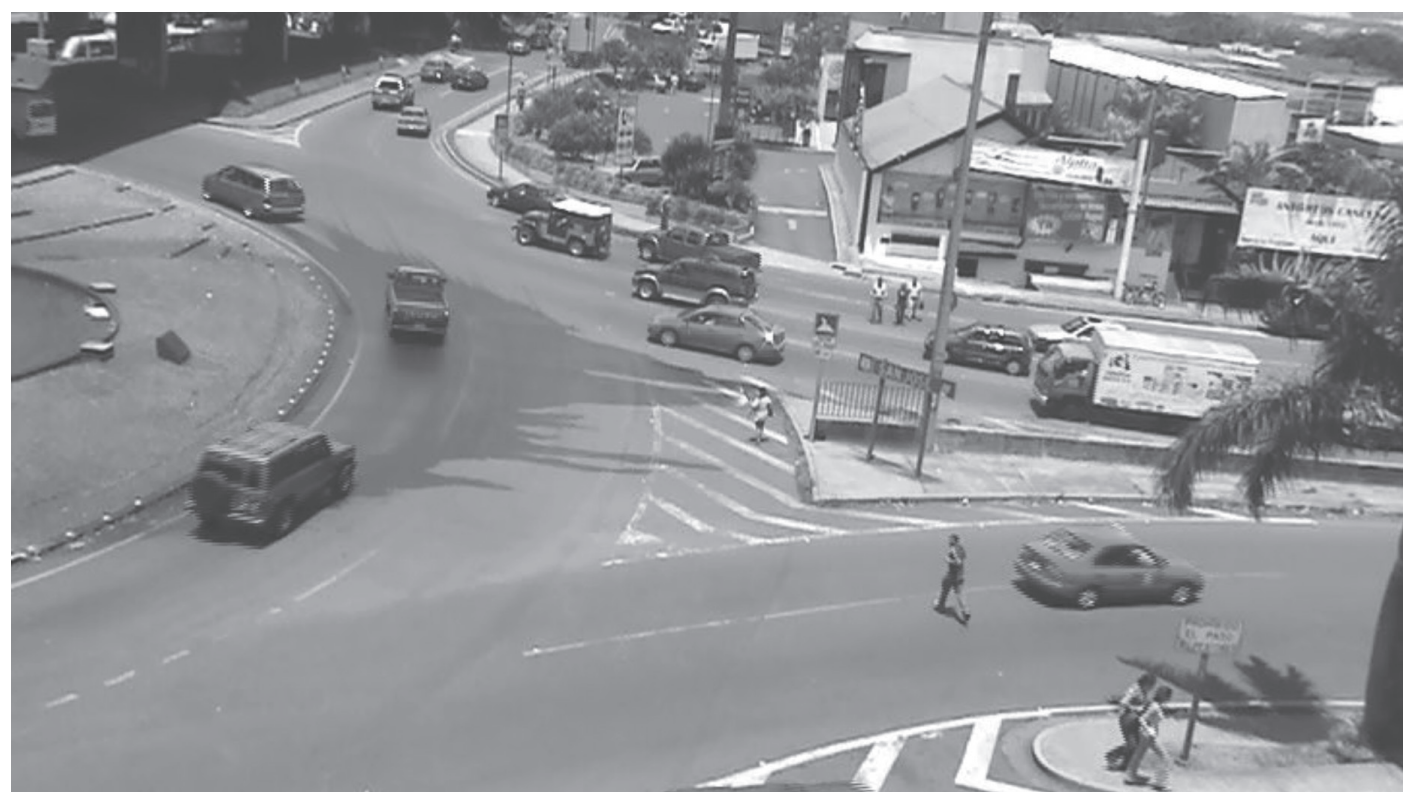

Por otra parte, la entrada al establecimiento comercial, esta bordeada de maceteros unidos entre sí por cadenas que impiden la salida y entrada de peatones, lo que a su vez constituye una clara violación del espacio público.

En segundo lugar, se da el irrespeto a la infraestructura para peatones, incluyendo aceras, donde se ven parqueados automóviles que obstaculizan el paso, obligando a los peatones a caminar por las calles, $y$ los cruces peatonales, en sitios como el ubicado entre el Outlet Mall y la Iglesia de San Pedro, producto del irrespeto de las y los conductores, así como la falta de planificación de la ubicación de las estaciones de autobús. Constantemente, las y los peatones deben cruzar en medio de autobuses y automotores ya sea que estén detenidos o en circulación. Y muchos conductores arremeten contra los peatones, acelerando cuando el semáforo se acaba de poner en rojo o cruzando indebidamente en dirección Norte-Este.

En Costa Rica existe un profundo rezago en términos de concebir el acceso a la movilización segura como un derecho para todas $y$ todos los usuarios y especialmente, para las personas de clase trabajadora. Niños, niñas, personas jóvenes, adultos mayores, mujeres y estudiantes son además de la mayoría de las personas de a pie, el grueso constitutivo de la sociedad costarricense y Acaminar clama por que se detenga el irrespeto a sus derechos, porque se les provea de infraestructura y proclama que se vele por el cumplimiento de sus necesidades $y$ porque se les otorgue no solo el beneficio, sino el derecho que les ha sido históricamente vedado, en la mayor parte de las vías públicas del país, y que nos recuerda día a día la gran cantidad de corazones pintados por las calles.

\section{DISCUSIÓN}

En este apartado se va a discutir los resultados del encuentro promovido por el Instituto de Investigaciones Sociales de la Universidad de Costa Rica, al cual asistieron las tres agrupaciones antes mencionadas. A su vez, el encuentro forma parte de los propósitos de la investigación titulada Dimensiones socioculturales del malestar vial en Costa Rica desde 
la cual se adopta una perspectiva crítica hacia toda lógica de movilización humana que se sostenga sobre la base de prácticas perjudiciales para el ambiente, la salud y la vida humana, desde un marco conceptual que permita defender el principio de la igualdad de oportunidades en el acceso a medios de transporte y la justicia en la distribución del espacio público.

Primero, los miembros del ACCR lamentaron la situación actual de la movilización humana en Costa Rica y manifestaron su preocupación ante la gran cantidad de muertes en carretera que se están produciendo y por el consumo cada vez más alto de automóviles, lo que hace insostenible su circulación por las carreteras del país. También comentaron el lanzamiento de campañas para el uso de dispositivos de seguridad vial y que lideraron una investigación que analizó el riesgo en carreteras, y que tiene como objetivo diseñar medidas de seguridad acordes a las necesidades de cada país. Dicha investigación fue financiada por la Sociedad y el Banco Mundial así como por la FIA.

Posteriormente, Aconvivir comentó los logros de la organización así como, los retos que día a día enfrenta tratando de negociar con políticos locales, representantes populares y empresas, por la procura de mejores condiciones de tránsito para ciclistas y otros tipos de usuarios. Por ejemplo, Aconvivir participó en la Reforma a la Ley de Tránsito por las Vías Públicas Terrestres solicitando que la distancia obligatoria entre ciclistas $y$ automovilistas en carreteras fuera de un metro y medio. Sin embargo, si bien los representantes del Estado no acataron la solicitud en toda su extensión, al menos sí se incluyó una normativa al respecto para que se respetara $90 \mathrm{~cm}$ como mínimo, en la ley.

Los representantes de Aconvivir lanzaron la pregunta de por qué a los ciclistas se les prohíbe circular por las principales carreteras del país, pero no se les provee de rutas alternativas. Es decir, ¿con base en qué fundamentos se limita el acceso y el derecho al libre tránsito para estos tipos de usuarios? Debe decirse que cuando hay automóviles circulando rápido, existe un riesgo para ciclistas y peatones de ser tirados por una fuerza de succión. Además, de poner en serio cuestionamiento los valores de un país donde priman los valores de la velocidad por encima de la salud y el bienestar de los individuos; el Estado cae en incumplimiento de su obligación de proveer rutas alternativas para otros tipos de usuario, dado que las vías públicas no deben fundamentarse sobre la base de un acceso excluyente. Por ejemplo, decía el representante de Aconvivir, que muchas personas tienen como único medio de transporte para trasladarse a los lugares de empleo $y$ de estudio, la bicicleta, dado que les es imposible cubrir el costo de los pasajes de transporte colectivo.

Acaminar nos recuerda que a mayor cantidad de personas a pie, menor riesgo en todos los sentidos. Primero, menor riesgo de siniestro en tanto a mayor cantidad de automóviles en circulación, mayor riesgo de siniestro, a mayor número de peatones $y$ peatonas menos vehículos en circulación. Además, más salud física $y$ mental, pues caminar trae beneficios como el fortalecimiento de los músculos, una mejor irrigación sanguínea, la purificación de nuestros pulmones en ambientes no contaminados y más felicidad, pues el deporte ayuda a sentirse mejor a las personas. También entre más personas a pie, más posibilidades de interacción social. A esto se suma que si más personas caminamos por las vías públicas, tendremos más posibilidades y potencial de fuerza para que se construya infraestructura peatonal. La infraestructura peatonal y el respeto a los peatones es un derecho de la ciudadanía y un deber del Estado, una forma de promover la salud de la población y de reducir los congestionamientos así como, un reductor de la violencia social dado que una de sus fuentes radica en el hacinamiento y la contaminación visual y auditiva que causan los automotores. El derecho al espacio público es una necesidad de primer orden.

Finalmente, si bien Aconvivir y Acaminar, plantearon las diferencias en los objetivos de sus organizaciones, en tanto, mientras para Aconvivir son los usuarios de vehículos no automotores y de a pie, para Acaminar son su principal foco de interés las personas a pie $y$ las personas con menores ingresos económicos, ambas instancias se declararon organizaciones amigas al igual que lo hicieron con 
la FIA, por lo que al final del encuentro, las tres organizaciones acordaron encontrarse un año más tarde para discutir los avances en las agrupaciones $y$ promover futuros encuentros de coordinación para el alcance de las metas comunes. Ojalá se sumen muchas otras organizaciones para la siguiente actividad y podamos ver más de los avances de estas.

\section{CONCLUSIONES}

Las organizaciones alternativas de movilización o transportes, surgen para suplir ciertas necesidades y demandas específicas que por alguna razón, no están siendo satisfechas por las instituciones estatales, las empresas, organizaciones y la sociedad en general. Pero para alcanzar sus objetivos, requieren que más personas se sumen a ellas, por lo que se facilitan los enlaces para contactarlas si al lector o lectora del presente artículo le interesa participar en alguna de ellas, después de conocer sus objetivos $y$ acciones comprometidas.

También se considera que organizaciones como estas constituyen grupos de intereses específicos fundamentales en la democratización del derecho al espacio público, la promoción del bienestar y la salud, la lucha por una sociedad más justa en términos distributivos. En este sentido, la sociedad tiene tres posibilidades para hacer frente a las lesiones y las muertes del tránsito: prevenir, actuar mediatamente o paliar. Ya es hora de que la prevención esté de primera a la orden del día y de que comprendamos que la prevención de siniestros es sinónimo de lucha contra las desigualdades del sistema y el primer paso para la construcción de una sociedad más sana, que permita a sus miembros crecer, vivir, desarrollarse y potenciar sus habilidades. El transporte no es solo un medio para lograr esto, debe concebirse como un fin en sí mismo, pues llegar sanos a casa es el principio para un mejor presente, un futuro prometedor y empezar a enmendar los errores del pasado, en nombre de todas sus víctimas.

Uno de los tantos aspectos positivos de organizaciones como Aconvivir y Acaminar, es que en estas entidades se lucha por los dere- chos de las mayorías, que sin embargo, han sido históricamente olvidados a la hora del planeamiento y la ejecución de obras públicas para transportes y de la educación y planificación en seguridad vial. También la FIA lucha por que se implementen medidas de seguridad para los usuarios de las vías públicas. Estas organizaciones tienen muchas ideas y recomendaciones para contribuir a resolver necesidades infraestructurales, ambientales y sociales de la movilidad humana. Estas agrupaciones han hecho trabajo de hormiga para atender necesidades sentidas de la población y tienen algunos planes de ejecución importantes, como la implementación de ciclovías en todo el país. Particularmente, Aconvivir y las instituciones amigas de la entidad diseñaron una ciclo vía en doble sentido de San José a La Sabana, que solo requiere del apoyo político y del Estado, así como, de la Sociedad Civil para materializarlos.

Finalmente, solo resta recalcar la importancia de que la Universidad siga aprovechando los espacios de conmemoración y celebración de actividades como el Día sin Humo, para efectuar reflexiones académicas y de concientización social, de la mano con organizaciones de la sociedad civil. De tal modo que se subraye la importancia de tomar medidas para la prevención de problemas sociales y de la salud, como lo son los siniestros del tránsito así como, para convencer a las autoridades de que invertir en diseños e infraestructura seguros no es un gasto sino que debería ser el principal propósito de la responsabilidad que se les ha encomendado, en representación de todos los sectores y las clases sociales.

\section{BIBLIOGRAFÍA}

Sánchez, A. "Reflexiones sobre el estudio de las violencias en los procesos de movilidad humana". Transportation: Theory and Aplication 2 (1). 2010: 42-70.

Vargas; Maikel y Solano, Leslie. "Accidentes de tránsito fatales en el 2007 en Costa Rica". Med. leg. Costa Rica 25 (2). Setiembre 2008: 07-24. [Documento en línea]. 
Disponible en: <http://www.scielo.sa.cr/> [citado 08 junio 2010].

\section{SITIOS}

Acaminar. <http://www.acaminar.org/>

Aconvivir. <http://www.aconvivir.org/>
Automóvil Club de Costa Rica. <http://www. automovilclubcr.com/>

Federación Internacional de Automovilismo, 2008. <http://www.fia.com/>

Federación Internacional de Peatones. <http:// www.pedestrians-int.org/> 
